\title{
Step-wise approach to prevention of chronic diseases in the Danish primary care sector with the use of a personal digital health profile and targeted follow-up - an assessment of attendance
}

Lars Bruun Larsen ${ }^{1 *}\left(\mathbb{D}\right.$, Jens Sondergaard ${ }^{1}$, Janus Laust Thomsen ${ }^{2}$, Anders Halling ${ }^{3}$, Anders Larrabee Sønderlund ${ }^{1}$, Jeanette Reffstrup Christensen ${ }^{1}$ and Trine Thilsing ${ }^{1}$

\begin{abstract}
Background: Current evidence on chronic disease prevention suggests that interventions targeted at high-risk individuals represents the best way forward. We implemented a step-wise approach in the Danish primary care sector, designed for the systematic and targeted prevention of chronic disease. The intervention centered on a personal digital health profile for all participants, followed by targeted preventive programs for high-risk patients. The present paper examines individual characteristics and health-care usage of patients who took up the targeted preventive programs in response to their personal digital health profile.
\end{abstract}

Methods: A sample of patients born between 1957 and 1986 was randomly selected from the patient-list system of participating general practitioners in two Danish municipalities. The selected patients received a digital invitation to participate. Consenting patients received a second digital invitation for a personal digital health profile based on questionnaire and electronic patient record data. The personal digital health profile contained individualized information on risk profile and personalized recommendations on further actions. If at-risk or presenting with health-risk behaviour a patient would be advised to contact either their general practitioner or municipal health centre for targeted preventive programs. Attendance at the targeted preventive programs was examined using Poisson regression and chi-squared automatic interaction detection methods.

Results: A total of 9400 patients were invited. Of those who participated (30\%), 22\% were advised to get a health check at their general practitioner. Of these, $19 \%$ did so. Another $23 \%$ were advised to schedule an appointment for behaviour-change counselling at their municipal health centre. A total of 21\% took the advice. Patients who had fair or poor self-rated health, a body mass index above 30, low self-efficacy, were female, non-smokers, or lead a sedentary lifestyle, were most likely to attend the targeted preventive programs.

Conclusions: A personal digital health profile shows some promise in a step-wise approach to prevention in the Danish primary care sector and seems to motivate people with low self-efficacy to attend targeted preventive programs.

Trial registration: Registered at Clinical Trial Gov (Unique Protocol ID: TOFpilot2016). Prospectively registered on the 29th of April 2016.

Keywords: Health promotion, Indicated prevention, Integrated prevention

\footnotetext{
* Correspondence: Iblarsen@health.sdu.dk

1 Department of Public Health, Research Unit of General Practice, University

of Southern Denmark, J.B. Winsløws Vej 9A, 5000 Odense, Denmark

Full list of author information is available at the end of the article
}

(c) The Author(s). 2019 Open Access This article is distributed under the terms of the Creative Commons Attribution 4.0 International License (http://creativecommons.org/licenses/by/4.0/), which permits unrestricted use, distribution, and

reproduction in any medium, provided you give appropriate credit to the original author(s) and the source, provide a link to the Creative Commons license, and indicate if changes were made. The Creative Commons Public Domain Dedication waiver (http://creativecommons.org/publicdomain/zero/1.0/) applies to the data made available in this article, unless otherwise stated. 


\section{Background}

General health checks to prevent type-2 diabetes mellitus (T2DM) and cardiovascular disease (CVD) have shown no population-level effects above and beyond those attained by opportunistic case finding [1, 2]. However, it is well-known that as the absolute risk of CVD increases, so too does the protective effect of both health-behaviour change and preventive treatment [3-5]. This suggests that taking a more targeted approach to the prevention of chronic diseases, with a focus on high-risk individuals, may be warranted [6]. Advanced digital technology and infrastructure have only recently made such targeted approaches possible without putting too much strain on available human and economic resources. Most importantly, these advances may facilitate individual risk assessment using information already available in healthcare databases or non-clinical health information. Examples of this added utility include the English National Health Services (NHS) in their health check program [7], as well as the Dutch cardio-metabolic disease (CMD) program [8].

Based on a technical feasibility study of a non-laboratory-based risk assessment from 2012 we designed the TOF (Danish acronym for Early Detection and Prevention) intervention [9]. TOF is a step-wise approach to systematic and targeted prevention of T2DM, CVD and chronic obstructive pulmonary disease (COPD), designed for the Danish primary health-care system. The intervention has two elements: a general and a targeted intervention. The general intervention involves the creation of personal digital health profiles for each individual in the entire study population. The targeted intervention involves a health check at the general practitioner (GP) or behaviour-change counselling at a municipal health centre (MHC). The targeted intervention applies only to those patients who were deemed likely to benefit from such intervention due to either their high, overall risk of the aforementioned diseases, or because they regularly engaged in health-risk behaviours. The TOF intervention was tested for acceptability, feasibility, and short-term effects in a large-scale pilot study during the period from April 2016 to December 2016 [10].

To our knowledge, only two studies have evaluated the uptake of similar, step-wise approaches (web-based risk assessment, risk-based referral) to preventive programs aimed at cardio-metabolic disease (CMD) or CVD $[8,11]$. However, neither of the two studies reported on patient characteristics or health-care usage in the context of program attendance. In this study we therefore set out to examine attendance in targeted preventive programs in the Danish primary care sector in response to a personal digital health profile.

\section{Methods}

Design

A cross-sectional analysis of attendance at the targeted intervention of the TOF pilot study.

\section{Setting}

The TOF pilot study took place in the municipalities of Varde and Haderslev from May 2016 to December 2016. The municipalities of Varde and Haderslev are two average-sized rural municipalities (approx. 50.000 inhabitants) in the Region of Southern Denmark. A total of 68 GPs resided in the two municipalities. Primary disease prevention such as smoking cessation, dietary advice, physical activity, and treatment of alcohol addiction falls under the responsibility of MHCs and is performed by qualified health professionals including nurses, dieticians, occupational therapists, and physiotherapists. Secondary disease prevention, such as preventive medical treatment and patient education in chronic disease management, is shared between the municipalities and the regional health authorities and is generally undertaken by GPs. Danish GPs are organised in publicly funded and privately-owned clinics with an average of two GPs per clinic. Each clinic employs a patient-list system with an average of 1600 patients per GP [12].

\section{Population}

The study base comprised people born between 1957 and 1986 (age 29 to 60). The source population was specified in March 2016 using the Regional Primary Care Administrative System and included 200 patients randomly selected from each of the participating GPs' patient list system irrespective of the postal code of the patient's residence. The study population was eventually made up of patients who resided in the municipalities of Varde or Haderslev and could be reached by digital mail.

\section{Recruitment}

In April 2016, an initial, digital invitation and informed consent form was sent to the study population. The consent form included participant permission to access specific patient International Classification of Primary Care (ICPC-2) codes and Anatomical Therapeutical Chemical (ATC) codes for information about diagnoses and medical prescriptions, respectively. These records were retrieved from participating GPs' EPRs. Consenting patients were sent a second digital invitation in September 2016 to fill in a questionnaire on health-risk behaviours, family history of disease, early symptoms of COPD and osteoarthritis. A personal digital health profile was then created for each participant based on the information from their GP's EPR system and their questionnaire response and accessed on a webpage. 


\section{The personal digital health profile}

The personal digital health profile was inspired by research on preventive electronic patient records (EPR) and iteratively co-designed [13-15]. The personal digital health profile provided clear and concise personalised health information, recommendations for further action, including the advice to take up targeted preventive program at the GP or municipality, when relevant, short and concise facts about health-risk behaviour, information about the positive impact of behaviour-change, as well as a personalised list of available and relevant behaviour-change interventions. The aim of the personal digital health profile was fourfold and centered on: 1) motivating and enabling patients who would not otherwise have taken up a targeted intervention as the one offered here, 2) motivating and enabling people with poor self-management skills to take up the targeted intervention, 3) guiding patients with good self-management skills to change their own behaviour, and 4) keeping the healthy, low-risk population from demanding unnecessary health checks from their GP.

\section{The targeted intervention}

Based on EPR and questionnaire information, patients were stratified to one of four groups: Group one consisted of patients who had received treatment for hypertension, hyperlipidaemia, type- 2 diabetes mellitus (T2DM), CVD, and/or COPD (as indicated by relevant ICPC-2 and ATC codes) at their GP. These patients were not provided any intervention beyond usual care. Group two included patients who were deemed to benefit from a health check at their GP as determined by three risk algorithms for T2DM, CVD, and COPD [16-18]. As such, these patients were advised to schedule a health check with their GP. The health check comprised a medical examination and a subsequent health counselling session. The health counselling was scheduled as a 30-min session. Group three comprised patients who were not flagged by the risk algorithms, but who had a BMI above 35, and/or reported that they regularly engaged in health-risk behaviour, including daily smoking, high-risk alcohol consumption, unhealthy dietary habits, and sedentary leisure time activities. Patients stratified to group three were advised to schedule a 15-min initial telephone-based counselling session at their municipal health centre (MHC). This could be requested online via their personal digital health profile. If deemed relevant, a one-hour face-to-face behaviourchange counselling session could be scheduled to follow up the initial one. On indication, the patient would be referred to a behaviour-change intervention at the MHC or their GP for medical treatment. Finally, group four consisted of patients with a healthy lifestyle and no need for further intervention.

\section{Analysis}

Outcomes

We report on two outcomes. Firstly, we examined attendance or non-attendance at the targeted GP-based health check (Group two). Attendance was defined as having received the medical examination. Secondly, we looked at attendance or non-attendance at the MHCbased counselling session (Group three). Here, attendance was defined as having received the initial telephone-based counselling.

\section{Exposures}

Exposures included socio-demographic information, mental wellbeing, self-efficacy, health beliefs, health-risk behaviours, BMI, and health-care usage at their GP. Socio-demographics were derived from the national Danish bureau of statistics (Statistics Denmark). Mental well-being, self-efficacy, and health beliefs were derived from a questionnaire presented to all those patients who consented. Data on health-risk behaviours were obtained from the questionnaire which formed the basis for the personal digital health profile. Information on past health checks was retrieved from their GPs' EPR system. EPR and questionnaire information related purely to consenting patients. All variables were linked by the patients' unique Danish Personal Identification numbers (CPR) and pseudonymized before being accessible on a secure server at Statistics Denmark.

\section{Socio-demographics}

Age was categorised into one of two age groups: age 29 to 44 or 45 to 60 . Country of origin was determined for the year 2016 and categorised as 'Danish' or 'non-Danish' origin. Cohabitational status was similarly determined for the year 2016 and categorised as 'cohabiting' or 'single'. Educational attainment for October 2015 was categorised as a binary variable: secondary school and high school, or vocational education and higher education. Employment status for November 2014 was categorised as 'employed' or 'unemployed'. Employed included both employed and self-employed. Unemployed included people on unemployment benefits or who received any form of social welfare or pension. Relative poverty was determined from the households' annual net income in the years 2013, 2014 and 2015, and defined as below $50 \%$ of the median.

\section{Health-risk behaviours and biomarkers}

Health-risk behaviours and BMI were all dichotomised. Thus, BMI was categorised as either $\mathrm{BMI} \geq 30$ or $\mathrm{BMI}<30$. Smoking status was defined as being a current smoker (daily or occasional) or not (stopped or never). As the group of patients with high-risk alcohol consumption comprised few patients, alcohol consumption was split 
into being above or below low-risk. Low-risk alcohol consumption was set according to Danish guidelines as 7 units/week for women and 14 units/week for men [19]. Physical activity was divided into sedentary or active during leisure time. Active leisure time activity was defined as 4 hours or more of low- to high-intensity leisure time activity (gardening, walking the dog, cycling, etc.) a week. In contrast, sedentary leisure time activity was defined as reading, watching television or other sedentary activities during leisure time. Finally, diet was dichotomised as unhealthy diet or otherwise. Unhealthy diet was defined as a score of four or lower on a 12-point dietary scale [20].

\section{Phychological measures}

Mental wellbeing was measured using the metrics converted Short Warwick-Edinburgh Mental Wellbeing Scale (SWEMWBS) (range 7 to 35) [21]. Self-efficacy was measured using the generalised self-efficacy scale (range 0 to 40) [22]. Health beliefs were measured on a scale ranging from 4 to 16 and derived from four questions on the perceived importance for health of smoking, diet, alcohol consumption, and physical activity. Each question was phrased as follows" How important for your health do you consider [health-risk behaviour] to be?" with four possible answers (not important, little importance, important, very important) scored from one (not important) to four (very important). The higher the score, the better the mental wellbeing, self-efficacy, and health beliefs.

\section{Health-care usage}

Previous attendance at the GP was retrieved from their GP's EPR and defined as having contacted their GP during the two-year period from May 2014 to April 2016 either in-person or by phone. Preventive health checks were defined as having had two or more of the belowmentioned values measured at their GP in the same consultation within a period of 2 years before consenting to the study (May 2014 to April 2016): blood pressure (systolic or diastolic blood pressure), lung function (Forced expiratory volume (FEV1), Forced vital capacity (FVC) or FEV1/FVC), glycated haemoglobin (HbA1c), or lipids (total cholesterol, HDL or LDL).

\section{Statistical analysis}

A one-way ANOVA was used to compare means of numerical exposure variables between the four stratification groups. Chi-square tests were used to compare differences between binary variables. Age, sex, and health-risk behaviours were not compared between the four stratification groups as they were used to determine group belonging. Attendance correlates are presented as crude estimates for all exposure variables (Model 1) as well as estimates adjusted for age and sex (Model 2). We also adjusted exposure variables according to a Direct Acyclic Graph (DAG) causal model of attendance at health checks as conditional interdependencies between exposure variables posed a risk of either residual confounding or collider-stratification bias (Model 3) [23, 24]. We adjusted model 3 in order to avoid collider stratification bias, thus leaving room for possible residual confounding.

The crude estimates were analysed using Chi-square tests and presented as $p$-values. Adjusted estimates were analysed using Poisson regression with robust error variance and presented as incidence rate ratios (IRR), with 95\% confidence intervals $(\mathrm{CI})$ of the IRR, and p-values. We chose Poisson regression over logistic regression in order to generate IRR rather than odds ratios (OR) as IRR provides more intuitive estimates in cross-sectional analyses than OR [25]. Moreover, robust error variance was used to reach confidence intervals that are comparable to or superior to those reached from logistic regression [26, 27]. SWEMWBS, self-efficacy, and health beliefs were included in the statistical analyses as continuous variables of the overall score. All other exposure variables were included as categorical variables. Significance level was set at $p<0.05$.

We used a Chi-square Automatic Interaction Detector (CHAID) analysis to determine the relative strength of the available exposure variables (CHAID command in Stata) [28]. A CHAID analysis essentially uses multiple chi-squared analyses to group categories within each exposure variable into homogenous groups. From the homogenous groups, the CHAID analysis establishes a hierarchy of interactions between exposure variables with the most explanatory exposure variable ranked at the top of the hierarchy. Bonferroni corrections were applied to account for the Type I errors, which may result from multiple uses of chi-square tests. Certain merging, splitting, and stopping rules condition the resulting decision tree. Merging and splitting were given by the selected $p$-value of the Chi-squared analyses and the number of observations in the groups resulting from the Chi-squared analyses. In this study the significance level of merging and splitting ( $\alpha_{\text {merge }}, \alpha_{\text {split }}$, and $P$-value) was set at $p<0.05$. Splitting happened if the number of observations in a node was above 20 (parent node). The CHAID analysis stopped splitting when the number of observations in a sub-category was below a certain threshold. In this study the threshold was set at ten observations (child node). We included two CHAID analyses in this study. One analysis inserted attendance or non-attendance at their GP as the outcome. The other analysis used attendance or non-attendance at the MHC as outcome. All analyses were performed in Stata 14.0.

\section{Results}

A total population of 9400 patients from 47 GPs (200 from each GP) was randomly selected to form the 
source population of the TOF pilot study (Fig. 1). Of this population, 586 patients were excluded from the sample as they could not be contacted by digital mail and/or resided outside of the municipalities of Varde or Haderslev. This resulted in a final study population of 8814 patients, of whom 3587 (41\%) consented to the study. Of these, 2661 patients (74\%) subsequently received a personal digital health profile. Of the 2661 patients, EPR information on 699 patients (26\%) indicated that they were diagnosed with, and/or receiving medical treatment for T2DM, CVD or COPD (group one). Based on the questionnaire and EPR information, 582 patients
(22\%) reached the cut-off of the three risk algorithms and were advised to consult their GP for a health check (group two). Another 618 patients (23\%) only exhibited health-risk behaviours and were advised to schedule an initial telephone-based counselling session with their MHC (group three). The rest of the cohort ( $n=762,29 \%)$ was not at high risk as per the risk algorithms, nor did they engage in health-risk behaviours (group four). Accordingly, they were advised to continue with their healthy lifestyle. Of those patients advised to consult their GP, 110 (19\%) did so. Similarly, for patients who exhibited health-risk

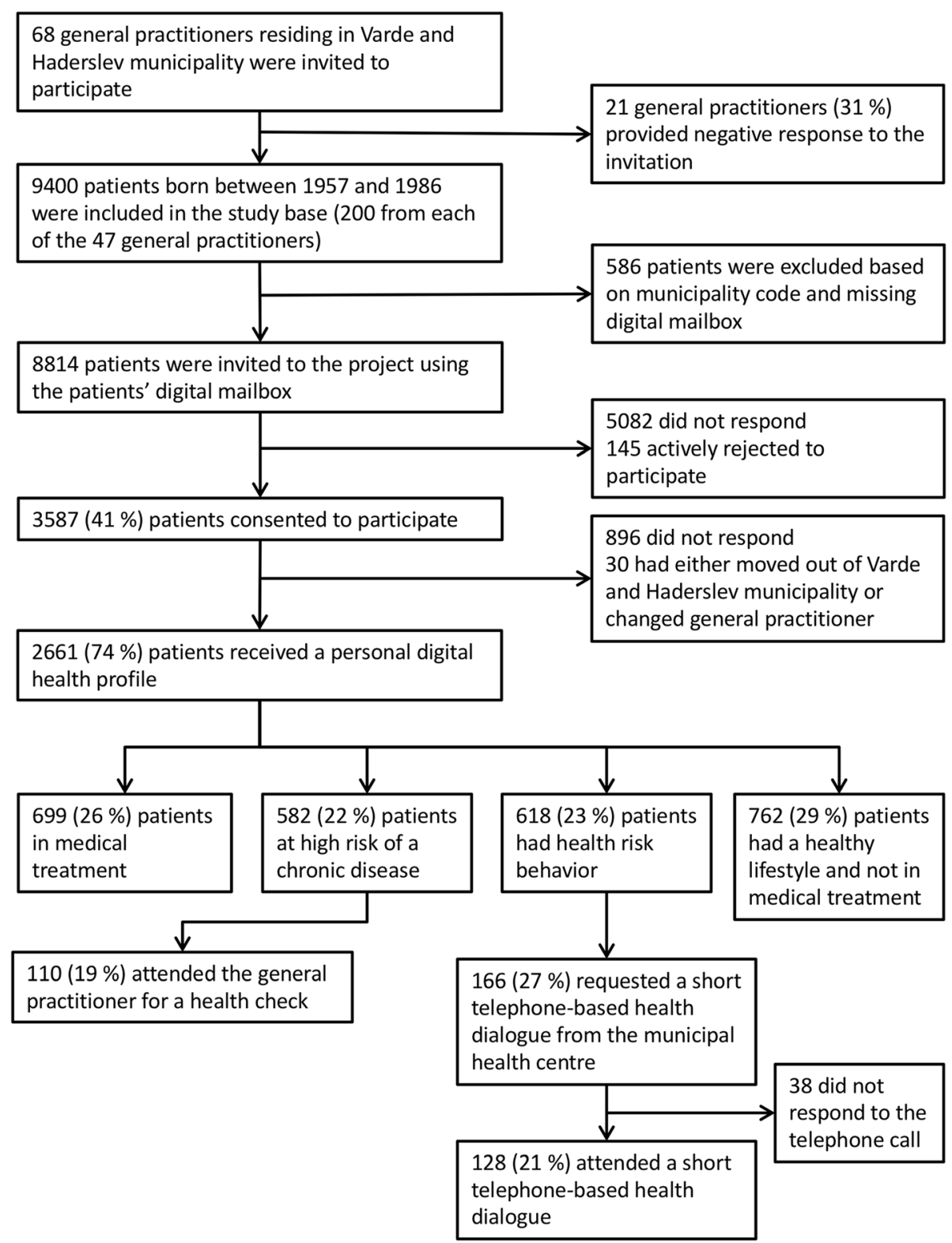

Fig. 1 Flow diagram of recruitment, stratification and attendance at the GP-based health check and the initial telephone-based counselling with the $\mathrm{MHC}$ 
behaviours, 128 (21\%) took the advice to get telephone-based counselling at the MHC.

\section{Comparisons of the four stratification groups}

The mean age of patients who received a personal digital health profile was 45.4 years. Within the group of patients who exhibited health-risk behaviours, the mean age was 42.8 years. Patients who were advised to consult their GP were on average 52.9 years old (Table 1). Overall, $44 \%$ of patients who received a personal digital health profile were men. However, men represented only $32 \%$ of those patients who did not engage in health-risk behaviour and were not in treatment (group four). Besides, men were overrepresented amongst patients advised to consult their GP (group two), in which 55\% were male.

Relative poverty was particularly prevalent among patients in the health-risk behaviour group. Furthermore, low educational attainment was particularly prevalent in patients advised to schedule a health check with their GP. Of these, $26 \%$ had attended a health check at their GP in the 2 years before receiving their personal digital health profile. Among patients who engaged in health- risk behaviour and who were advised to schedule a behaviour-change counselling session at the MHC, 17\% had received a health check during the past 2 years. On the other hand, $19 \%$ of patients with a healthy lifestyle and who were not in medical treatment had received a health check during the past 2 years. The prevalence of people of Danish origin did not differ across the four groups.

\section{Attendance and non-attendance at a GP-based health check (group two)}

Women and patients with sedentary leisure-time behaviour were more likely to attend a health check at their GP (Table 2). Moreover, lower self-efficacy was associated with a higher likelihood of getting a health check. Age, educational attainment, employment status, relative poverty, smoking status, alcohol consumption, dietary habits, self-rated health, mental wellbeing, beliefs in a healthy lifestyle, and having attended a health check during the past 2 years were not associated with the likelihood of attending a GP health check. The CHAID analysis of GP attendance rates indicated physical activity as the strongest predictor of attendance (Fig. 2). The

Table 1 Descriptive statistics of patient-characteristics and health-care usage in each of the four groups

\begin{tabular}{|c|c|c|c|c|c|}
\hline Patient characteristics & $\begin{array}{l}\text { In treatment } \\
\mathrm{n}(\%) \\
\text { (Group one) }\end{array}$ & $\begin{array}{l}\text { At high risk } \\
\mathrm{n}(\%) \\
\text { (Group two) }\end{array}$ & $\begin{array}{l}\text { Health-risk behaviour } \\
\mathrm{n}(\%) \\
\text { (Group three) }\end{array}$ & $\begin{array}{l}\text { No health-risk behaviour and } \\
\text { not in treatment } n(\%) \\
\text { (Group four) }\end{array}$ & Total n (\%) \\
\hline Total & $699(26)$ & $582(22)$ & $618(23)$ & $762(29)$ & $2661(100)$ \\
\hline Mean age $(\text { years })^{a}$ & 51.8 & 52.9 & 42.8 & 46.1 & 45.4 \\
\hline Male $^{a}$ & $332(47)$ & $319(55)$ & $270(44)$ & $243(32)$ & $1164(44)$ \\
\hline Danish origin* & $673(96)$ & $567(97)$ & $596(96)$ & $731(96)$ & $2567(96)$ \\
\hline Employed**** & $575(82)$ & $521(90)$ & $538(87)$ & $710(93)$ & $2343(88)$ \\
\hline Relative poverty**** & $99(14)$ & $61(10)$ & $120(19)$ & $71(9)$ & $351(13)$ \\
\hline Education (Secondary and high school) ${ }^{* * * *}$ & $145(21)$ & $131(23)$ & $109(18)$ & $88(12)$ & $473(18)$ \\
\hline Cohabiting ${ }^{* * * *}$ & $545(78)$ & $458(79)$ & $479(78)$ & $659(86)$ & $2141(80)$ \\
\hline Smokers $^{a}$ & $140(20)$ & $83(14)$ & $237(38)$ & $0(0)$ & $460(17)$ \\
\hline Alcohol risk behaviour (above low risk) ${ }^{a}$ & $92(13)$ & $72(12)$ & $73(12)$ & $57(7)$ & $294(11)$ \\
\hline Unhealthy diet (dietary score $0-4)^{a}$ & $166(24)$ & $132(23)$ & $337(55)$ & $0(0)$ & $635(24)$ \\
\hline Sedentary behaviour ${ }^{a}$ & $125(18)$ & $102(18)$ & $157(25)$ & $0(0)$ & $384(14)$ \\
\hline Body mass index $>30^{\mathrm{a}}$ & $210(30)$ & 229 (39) & $90(15)$ & $34(4)$ & $563(21)$ \\
\hline Self-rated health (Good, very good, excellent)**** & $555(79)$ & $506(87)$ & $536(87)$ & $728(96)$ & $2325(87)$ \\
\hline Mean mental well-being (total score) ${ }^{* * * *}$ & 23.9 & 24.4 & 23.9 & 25.0 & 24.2 \\
\hline Mean self-efficacy (total score) ${ }^{* * * *}$ & 29.7 & 30.3 & 30.1 & 31.2 & 30.3 \\
\hline $\begin{array}{l}\text { Mean beliefs in a healthy lifestyle } \\
\text { (total score)****}\end{array}$ & 13.2 & 13.1 & 12.9 & 14.1 & 13.3 \\
\hline Health check in past two years ${ }^{a}$ & $434(62)$ & $152(26)$ & $104(17)$ & $142(19)$ & $832(31)$ \\
\hline
\end{tabular}

${ }^{a}$ No statistical analysis as the variable was used in the risk stratification

${ }^{*} p>0.05$

${ }_{* *}^{*} p<0.05$

${ }^{* * *} p<0.01$

${ }^{* * * *} p<0.001$ 


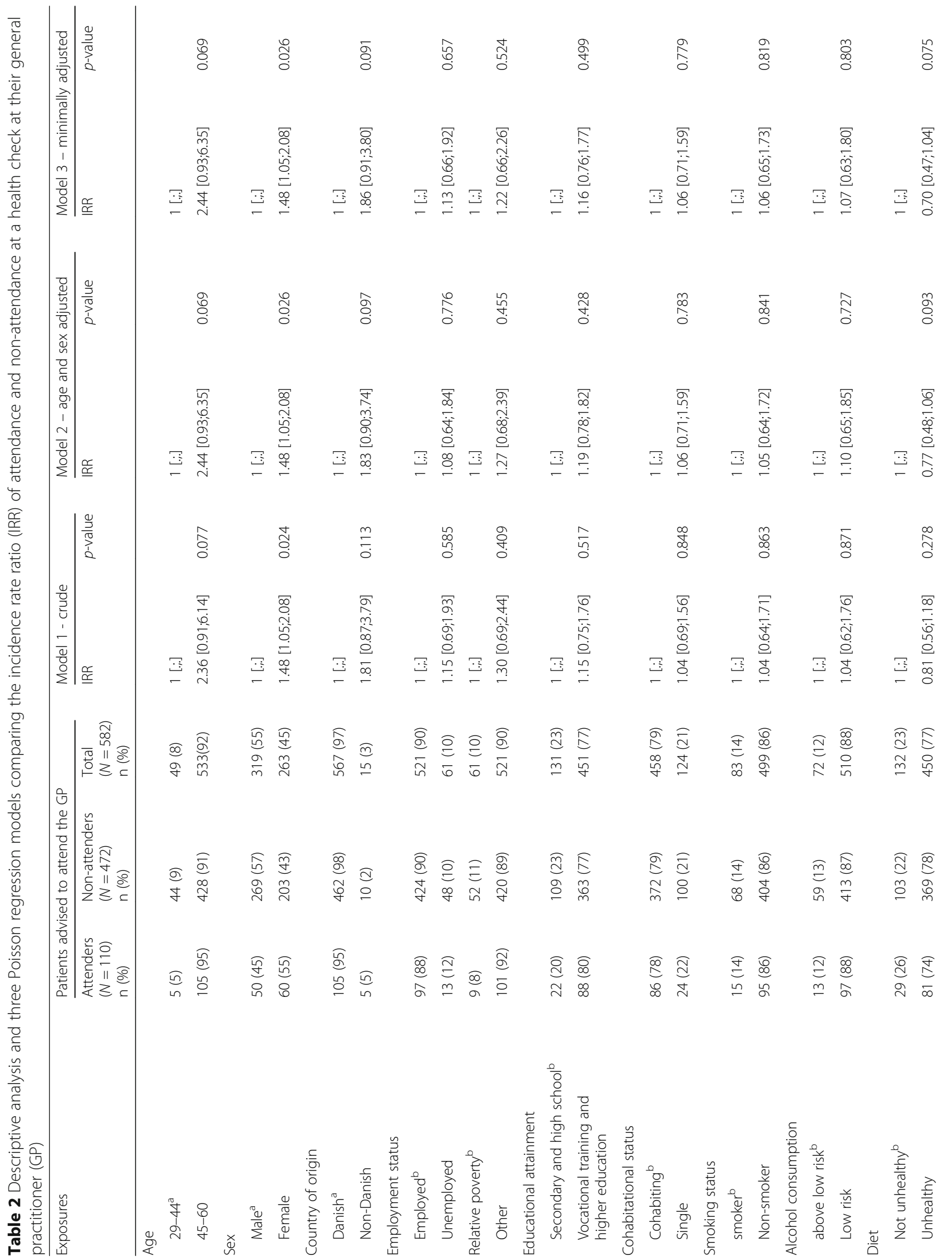




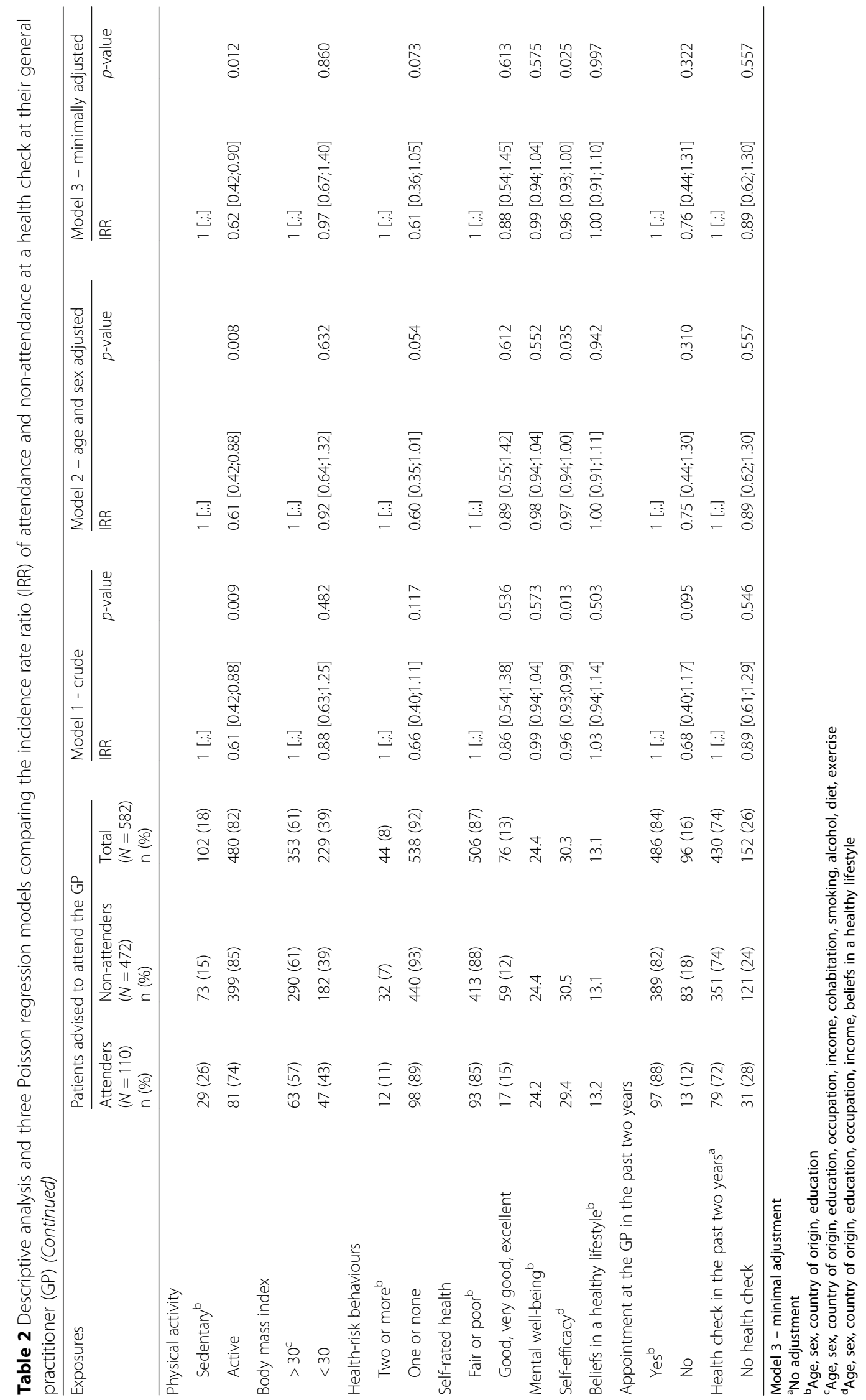


attendance rate among those with sedentary leisure-time behaviour was $28 \%$, whereas it was $17 \%$ among those who engaged in some form of leisure-time exercise.

\section{Attendance and non-attendance at an initial telephone-based counselling at the MHC (group three)}

Non-smokers, patients with BMIs above 30, and patients with poor or fair self-rated health were more likely to attend the initial telephone-based counselling session at their MHC than their smoking, below BMI 30, and good to excellent self-rated health counterparts (Table 3). Similar to attenders at the GP-based health check, lower self-efficacy was associated with a higher likelihood of having an initial telephone-based counselling session. There were no statistically significant associations between age, sex, educational attainment, employment status, relative poverty, alcohol consumption, dietary habits, mental wellbeing, beliefs in a healthy lifestyle, and/or having attended a health check in the past 2 years. The CHAID analysis showed that self-rated health was the strongest overall predictor of attendance, and smoking status was the strongest predictor among patients with fair or poor self-rated health (Fig. 2). The attendance rate was $34 \%$ among patients with fair or poor self-rated health, and 19\% among those with good to excellent self-rated health. Among patients with fair or poor self-rated health, $20 \%$ of smokers attended the initial telephone-based counselling session, whereas $42 \%$ of the non-smokers attended.

\section{Discussion}

The overall attendance rate was around $20 \%$ both for patients who were advised to schedule a health check at their GP (group two) and for patients who were advised to schedule a counselling session at the MHC (group three). Furthermore, our results show that being female, having sedentary behaviour and low self-efficacy were associated to attendance at a health check at their GP (group two). Among patients with health-risk behaviour (group three), non-smokers, patients with fair or poor self-rated health, low self-efficacy, or a BMI above 30 were most likely to attend the initial telephone-based counselling session. We saw no differences in age, educational attainment, employment status, relative poverty, or cohabitational status between attenders and non-attenders at either their GP or MHC. Moreover, as low self-efficacy was associated with higher attendance both at a GP health check and at an initial telephone-based counselling session with an MHC, the personal digital health profile appears to fulfil its aim of motivating and enabling people with low self-management capabilities to attend preventive services. However, it does not meet its other objective of motivating and enabling patients who had not had a health check or visited their GP within the past 2 years. Finally, our results also suggest that health checks provided by the GP as part of their daily clinical practice are currently not only targeted those patients who reached the cut-off of the risk algorithms as one out of five patients with no modifiable health-risk behaviours (group four) had received a health
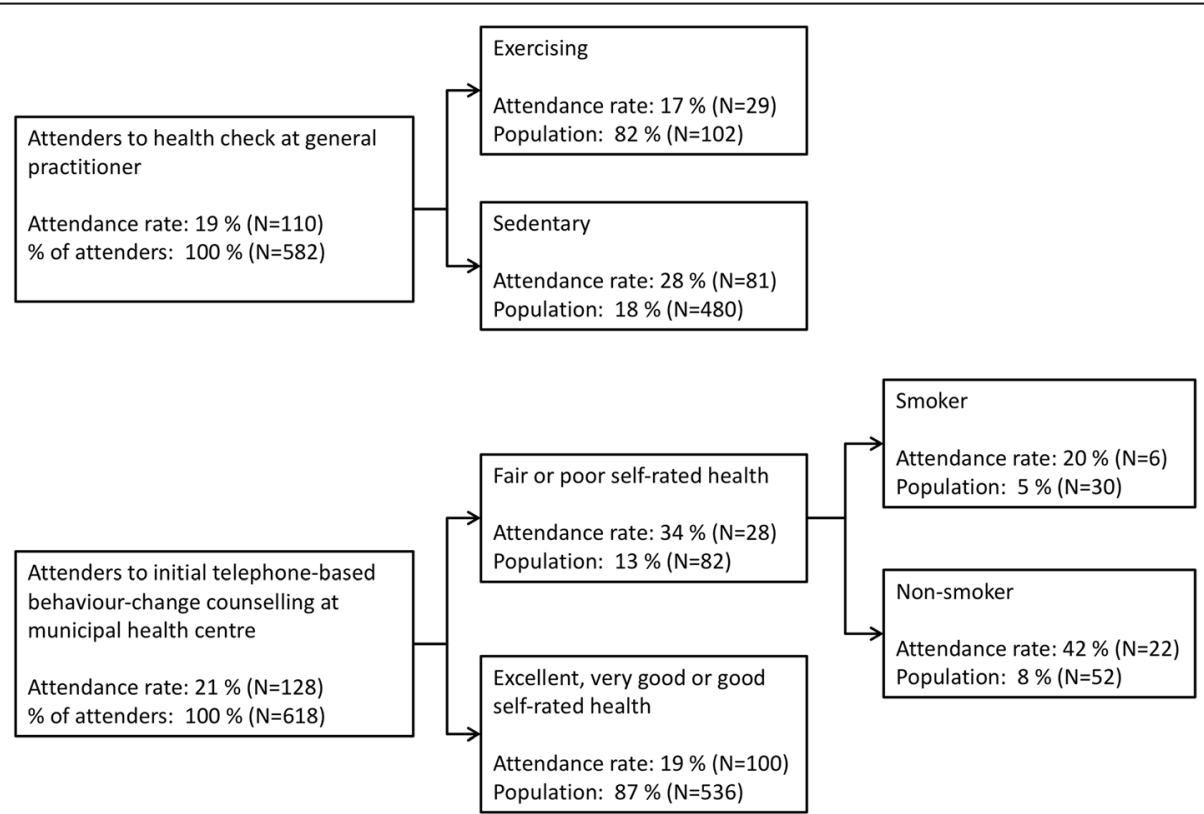

Fig. 2 Decision tree analysis of predictors of attendance or non-attendance at the GP-based health check and the initial telephone-based counselling with the MHC 
Table 3 Descriptive analysis and three Poisson regression models comparing the incidence rate ratio (IRR) of those patients who took up the initial telephone-based counselling with the Municipal health centre (MHC) and those patients who did not

\begin{tabular}{|c|c|c|c|c|c|c|c|c|c|}
\hline \multirow[t]{2}{*}{ Exposures } & \multicolumn{3}{|c|}{ Patients advised to attend MHCs } & \multicolumn{2}{|l|}{ Model 1 - crude } & \multicolumn{2}{|c|}{$\begin{array}{l}\text { Model } 2 \text { - age and } \\
\text { sex adjusted }\end{array}$} & \multicolumn{2}{|c|}{$\begin{array}{l}\text { Model } 3 \text { - minimally } \\
\text { adjusted }\end{array}$} \\
\hline & $\begin{array}{l}\text { Attenders } \\
(N=128) \\
\mathrm{n}(\%)\end{array}$ & $\begin{array}{l}\text { Non-attenders } \\
(\mathrm{N}=490) \\
\mathrm{n}(\%)\end{array}$ & $\begin{array}{l}\text { Total } \\
(N=618) \\
\mathrm{n}(\%)\end{array}$ & IRR & $p$-value & $\mathrm{IRR}$ & $p$-value & IRR & $p$-value \\
\hline \multicolumn{10}{|l|}{ Age } \\
\hline $29-44^{a}$ & $86(67)$ & $284(58)$ & $370[60)$ & $1[. .]$. & & $1[. . ;]$ & & $1[. . ;]$ & \\
\hline $45-60$ & $42(33)$ & $206(42)$ & $248(40)$ & $0.73[0.52 ; 1.01]$ & 0.060 & $0.73[0.52 ; 1.02]$ & 0.064 & $0.73[0.52 ; 1.02]$ & 0.064 \\
\hline \multicolumn{10}{|l|}{ Sex } \\
\hline Male $^{\mathrm{a}}$ & $59(46)$ & $211(43)$ & $270(44)$ & $1[\therefore]$ & & $1[\therefore]$ & & $1[\therefore]$ & \\
\hline Female & $69(54)$ & $279(57)$ & $348(56)$ & $0.91[0.67 ; 1.24]$ & 0.550 & $0.93[0.68 ; 1.27]$ & 0.650 & $0.93[0.68 ; 1.27]$ & 0.650 \\
\hline \multicolumn{10}{|l|}{ Country of origin } \\
\hline Danish $^{a}$ & $121(95)$ & $475(97)$ & $596(96)$ & $1[. .]$. & & $1[\therefore]$ & & $1[\therefore]$ & \\
\hline Non-Danish & $7(5)$ & $15(3)$ & $22(4)$ & $1.56[0.83 ; 2.95]$ & 0.165 & $1.62[0.87 ; 3.01]$ & 0.130 & $1.62[0.87 ; 3.01]$ & 0.130 \\
\hline \multicolumn{10}{|l|}{ Employment status } \\
\hline Employed $^{b}$ & $112(88)$ & $426(87)$ & $538(87)$ & $1[. .]$. & & $1[\therefore . ;]$ & & $1[\therefore]$. & \\
\hline Unemployed & $16(12)$ & $64(13)$ & $80(13)$ & $0.96[0.60 ; 1.53]$ & 0.861 & $0.95[0.59 ; 1.51]$ & 0.822 & $0.99[0.62 ; 1.57]$ & 0.953 \\
\hline \multicolumn{10}{|l|}{ Income } \\
\hline$(50 \% \text { below median income })^{b}$ & $22(17)$ & $98(20)$ & $120(19)$ & $1[\therefore]$ & & $1[\therefore]$ & & $1[\therefore]$ & \\
\hline Other & $106(83)$ & $392(80)$ & $498(81)$ & $1.16[0.77 ; 1.76]$ & 0.474 & $1.20[0.79 ; 1.83]$ & 0.401 & $1.21[0.78 ; 1.82]$ & 0.412 \\
\hline \multicolumn{10}{|l|}{ Educational attainment } \\
\hline Secondary and high school ${ }^{b}$ & $18(14)$ & $91(19)$ & $109(18)$ & $1[. .]$. & & $1[\therefore . ;]$ & & $1[. . ;]$ & \\
\hline $\begin{array}{l}\text { Vocational training and } \\
\text { higher education }\end{array}$ & $110(86)$ & $399(81)$ & $509(82)$ & $1.31[0.83 ; 2.06]$ & 0.242 & $1.28[0.81 ; 2.01]$ & 0.289 & $1.29[0.82 ; 2.04]$ & 0.275 \\
\hline \multicolumn{10}{|l|}{ Cohabitational status } \\
\hline Cohabiting $^{\mathrm{b}}$ & $97(76)$ & $381(78)$ & $478(77)$ & $1[. .]$. & & $1[. . \cdot]$ & & $1[. .]$. & \\
\hline Single & $31(24)$ & $109(22)$ & $140(23)$ & $1.09[0.76 ; 1.56]$ & 0.641 & $1.08[0.75 ; 1.55]$ & 0.675 & $1.11[0.77 ; 1.59]$ & 0.579 \\
\hline \multicolumn{10}{|l|}{ Smoking status } \\
\hline Smoker ${ }^{b}$ & $38(30)$ & $199(41)$ & $237(38)$ & $1[\therefore]$ & & $1[\therefore]$ & & $1[\therefore]$ & \\
\hline Non-smoker & $90(70)$ & $291(59)$ & $381(62)$ & $1.47[1.04 ; 2.07]$ & 0.028 & $1.44[1.02 ; 2.02]$ & 0.037 & $1.45[1.03 ; 2.04]$ & 0.032 \\
\hline \multicolumn{10}{|l|}{ Alcohol consumption } \\
\hline Above low risk ${ }^{b}$ & $115(90)$ & $430(88)$ & $545(88)$ & $1[\therefore]$ & & $1[\therefore . ;]$ & & $1[\therefore]$ & \\
\hline Low risk & $13(10)$ & $60(12)$ & $73(12)$ & $1.19[0.71 ; 2.00]$ & 0.517 & $1.13[0.67 ; 1.91]$ & 0.640 & $1.15[0.68 ; 1.95]$ & 0.613 \\
\hline \multicolumn{10}{|l|}{ Diet } \\
\hline Not unhealthy ${ }^{\mathrm{b}}$ & $78(61)$ & $259(53)$ & $337(55)$ & $1[\therefore . ;]$ & & $1[\therefore]$ & & $1[\therefore]$ & \\
\hline Unhealthy & $50(39)$ & $231(47)$ & $281(45)$ & $0.77[0.56 ; 1.06]$ & 0.110 & $0.79[0.57 ; 1.10]$ & 0.165 & $0.77[0.56 ; 1.07]$ & 0.116 \\
\hline \multicolumn{10}{|l|}{ Physical activity } \\
\hline Sedentary ${ }^{\mathrm{b}}$ & $34(27)$ & $123(25)$ & $157(32)$ & $1[\therefore . ;]$ & & $1[\therefore]$ & & $1[\therefore]$ & \\
\hline Active & $94(73)$ & $367(75)$ & $461(75)$ & $0.94[0.66 ; 1.32]$ & 0.708 & $0.96[0.67 ; 1.36]$ & 0.808 & $0.99[0.70 ; 1.41]$ & 0.960 \\
\hline \multicolumn{10}{|l|}{ Body Mass Index } \\
\hline$>30^{c}$ & $101(79)$ & $427(87)$ & $528(85)$ & $1[\therefore]$ & & $1[\therefore . ;]$ & & $1[\therefore]$ & \\
\hline$<30$ & $27(21)$ & $63(13)$ & $90(15)$ & $0.63[0.44 ; 0.90]$ & 0.012 & $0.65[0.45 ; 0.95]$ & 0.026 & $0.62[0.42 ; 0.91]$ & 0.014 \\
\hline \multicolumn{10}{|l|}{ Health-risk behaviours } \\
\hline Two or more & $19(15)$ & $68(14)$ & $87(14)$ & $1[\therefore]$ & & $1[\therefore]$ & & $1[\therefore]$ & \\
\hline One or none & $109(85)$ & $422(86)$ & $531(86)$ & $0.93[0.60 ; 1.43]$ & 0.738 & $0.96[0.62 ; 1.48]$ & 0.850 & $0.95[0.62 ; 1.47]$ & 0.821 \\
\hline
\end{tabular}


Table 3 Descriptive analysis and three Poisson regression models comparing the incidence rate ratio (IRR) of those patients who took up the initial telephone-based counselling with the Municipal health centre (MHC) and those patients who did not (Continued)

\begin{tabular}{|c|c|c|c|c|c|c|c|c|c|}
\hline \multirow[t]{2}{*}{ Exposures } & \multicolumn{3}{|c|}{ Patients advised to attend MHCs } & \multicolumn{2}{|l|}{ Model 1 - crude } & \multicolumn{2}{|c|}{$\begin{array}{l}\text { Model } 2 \text { - age and } \\
\text { sex adjusted }\end{array}$} & \multicolumn{2}{|c|}{$\begin{array}{l}\text { Model } 3 \text { - minimally } \\
\text { adjusted }\end{array}$} \\
\hline & $\begin{array}{l}\text { Attenders } \\
(N=128) \\
\mathrm{n}(\%)\end{array}$ & $\begin{array}{l}\text { Non-attenders } \\
(\mathrm{N}=490) \\
\mathrm{n}(\%)\end{array}$ & $\begin{array}{l}\text { Total } \\
(N=618) \\
\mathrm{n}(\%)\end{array}$ & IRR & $p$-value & $\mathrm{IRR}$ & $p$-value & $\mathrm{IRR}$ & $p$-value \\
\hline \multicolumn{10}{|l|}{ Self-rated health } \\
\hline Fair or poor ${ }^{b}$ & $28(22)$ & $54(11)$ & $82(13)$ & $1[\therefore]$ & & $1[. . \cdot]$ & & $1[. \therefore]$ & \\
\hline Good, very good, excellent & $100(78)$ & $436(89)$ & $536(87)$ & $0.55[0.39 ; 0.78]$ & 0.001 & $0.54[0.38 ; 0.77]$ & 0.001 & $0.53[0.37 ; 0.76]$ & 0.000 \\
\hline Mental well-being ${ }^{b}$ & 23.4 & 24.0 & 23.9 & $0.96[0.92 ; 1.01]$ & 0.089 & $0.97[0.93 ; 1.01]$ & 0.133 & $0.97[0.92 ; 1.01]$ & 0.115 \\
\hline Self-efficacy ${ }^{d}$ & 29.4 & 30.2 & 30.1 & $0.97[0.95 ; 1.00]$ & 0.078 & $0.97[0.94 ; 1.00]$ & 0.068 & $0.96[0.93 ; 0.99]$ & 0.015 \\
\hline Beliefs in a healthy lifestyle ${ }^{b}$ & 13.1 & 12.9 & 12.9 & $1.05[0.96 ; 1.13]$ & 0.287 & $1.05[0.97 ; 1.14]$ & 0.247 & $1.05[0.96 ; 1.14]$ & 0.279 \\
\hline \multicolumn{10}{|c|}{ Appointment at the general practitioner in the past two years } \\
\hline Yes $^{\mathrm{b}}$ & $114(89)$ & $421(86)$ & $535(87)$ & $1[\therefore]$ & & $1[\therefore]$ & & $1[\therefore]$ & \\
\hline No & $14(11)$ & $69(14)$ & $83(13)$ & $0.79[0.48 ; 1.31]$ & 0.361 & $0.77[0.46 ; 1.29]$ & 0.327 & $0.79[0.47 ; 1.32]$ & 0.364 \\
\hline $\begin{array}{l}\text { Health check at the general } \\
\text { practitioner in past two years }\end{array}$ & $101(79)$ & $413(84)$ & $514(83)$ & $1[\therefore]$ & & $1[\therefore]$ & & $1[\therefore]$ & \\
\hline No health check & $27(21)$ & $77(16)$ & $104(17)$ & $0.76[0.52 ; 1.10]$ & 0.142 & $0.73[0.51 ; 1.06]$ & 0.100 & $0.73[0.50 ; 1.05]$ & 0.090 \\
\hline
\end{tabular}

Model 3 - minimal adjustment

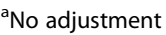

${ }^{b}$ Age, sex, country of origin, education

${ }^{\mathrm{C}} \mathrm{Age}$, sex, country of origin, education, occupation, income, cohabitation, smoking, alcohol, diet, exercise

${ }^{\mathrm{d}}$ Age, sex, country of origin, education, occupation, income, beliefs in a healthy lifestyle

check within the previous 2 years from being invited to the TOF pilot study.

\section{What is already known}

We saw an attendance rate of $20 \%$ at both the GP health checks and the initial telephone-based MHC counselling session. The two other known studies that have tested very similar interventions reported an attendance rate to a health check of $36 \%[8,11]$. However, the attendance rate reported in the study by Van der Meer et al. was unspecific about the online risk assessment and included not only high-risk patients but also patients at low and medium risk [11]. In the study of Van den Brekel-Dijkstra et al., the $36 \%$ comprised patients who had completed biometric measures at a research laboratory and not the GP. In the TOF pilot study we did not actively prompt the patients (e.g. with SMS messages or emails) to attend their GP or the MHC during the three-month study period. Prompting has been suggested to increase usage of digital technologies and could possibly have increased the attendance rate [29]. Moreover, pre-booked appointments have previously shown to increase the attendance rate at health checks, but due to technical limitations of the integration of multiple IT-systems, the recommendation to consult their GP or MHC had to be actively heeded by patients (i.e. they had to follow through and book their own appointments) [30]. Additionally, former health-care use has been reported as a reason for non-participation in preventive programs [31]. However, the personal digital health profile was not informed about former health-care usage on who had not had a follow-up on abnormal test results, had not had a health check or had not consulted their GP within the past years.

The study population comprised a selected group of patients who consented to participate in the TOF pilot study and received the personal digital health profile [32]. Our findings on patient characteristics and healthcare usage of attenders are, therefore, not directly comparable to the one-step combined risk-assessment and health-check approaches, which are used in many national programmes, including those in Germany, Australia, and South Korea. Nor are our results directly comparable to studies, which make no use of digital feedback on the initial risk assessment such as in the English NHS health check programme [33]. When that said, our results replicate former consistent findings on higher attendance at health checks among non-smokers and women [34-40]. In contrast, the finding that patients with sedentary behaviour are more likely to attend a GP health check differs from earlier studies, which either show no association with physical activity level $[11,34]$, or higher attendance among physically active patients [41]. Likewise, the finding that patients with a BMI above 30 are more prone to attend a telephonebased counselling session at the MHC, differs from the current evidence that suggests that BMI is not associated with attendance [11, 41], and that the non-obese are more prone to attend [34, 42]. The higher uptake of 
preventive programs among patients with fair or poor self-rated health differs somewhat from the current sparse and inconsistent evidence. Specifically, our results are at odds with past findings, which indicate that people with higher self-rated health are more likely to take up health checks [41], or that self-rated health is not associated with attendance [34]. Moreover, our findings of no association between attendance and age, and attendance and socio-economic status (SES) such as educational attainment, employment status and relative poverty, differ from previous studies, which show positive correlations between attendance and both age and SES $[23,38,41,43]$.

To our knowledge, self-efficacy has not been examined in relation to attendance at primary preventive programs. However, our results differ from evidence on attendance at rehabilitative services where uptake of cardiac rehabilitation either shows no association or an association with higher self-efficacy [44]. The link between self-efficacy and behaviour (including health behaviour) is represented by the fundamental notion that for an individual to engage in a behaviour, he/she must first be motivated to do so and feel capable of executing the given behaviour [45]. Past research suggests that in a health-behaviour context (including participation in prevention programmes), an individual's perception of his/ her own self-efficacy may be affected by social influences from peers, family, and health professionals, as well as by task-related factors such as planning and goal setting $[46,47]$. Thus, we hypothesise two avenues through which the personal digital health profile may have supported the attendance rate among patients with low self-efficacy: 1) By bringing to the fore a variety of health-related behaviour cues. For example, patients may have been motivated to engage in health behaviours (i.e. participation) by their mere interaction with the health professionals who invited them to participate in the study, generated their personal digital health profile, and were readily available for further support. 2) In a more direct manner, the concrete advice and guidance that patients were given in their personal digital health profile about why, how, and where to get a health check or behaviour-change counselling may also have endowed them with the knowledge to complete these tasks. That is, continuously showing participants the way to take preventive action step by step, may have framed the task of getting a health check as surmountable and manageable. By contrast, without all this information and support from the personal digital health profile, individuals with perceived low self-efficacy may have viewed the same task as too difficult to complete. As such, the interaction with health professionals combined with the information about one's own health (risk assessment) may have motivated people to do something, whereas the guidance, which the personal digital health profile offers, may have facilitated the individual's translation of that motivation into action (enabled them).

Further research is warranted to test this hypothesis, as well as research on the association of personal digital health profiles with motivation and enablement among those with e.g. low self-efficacy.

\section{What this study adds}

In a related paper we showed that the response to the first digital invitation and subsequent consent to participate in the TOF pilot-study was skewed towards higher uptake among women, the older people, and patients with higher SES [32]. However, this study suggests that a personal digital health profile may help foster a more equitable uptake of preventive programs in the primary care sector - especially among patients with lower selfefficacy and fair to poor self-rated health.

Previous studies on prevention in the primary care sector have mostly focused on either health checks or behaviour-change counselling [48-50]. However, recent studies report on interesting, though inconclusive, results on linking primary care and community health $[51,52]$. Our findings suggest that personal digital health profiles may be a valuable asset in the recruitment of patients to preventive programs across primary care providers.

However, the evidence is sparse on the reach and effects of personal digital health profiles used for preventive programs in the primary care sector, indicating that further research on personal digital health profiles, as part of a comprehensive approach to preventive programs in the primary care sector, is needed.

\section{Strengths and limitations}

A major strength is the use of high quality national health and social registries with very few missing observations combined with complete and comprehensive self-reported patient information and EPR information from their GP $[53,54]$. Another strength is the randomized source population. However, low and skewed initial participation led to a study population with more women, and higher average SES and age than in the randomized source population [32].

As much as a digital approach to the patient may make use of behaviour-change techniques to increase usage, it may also be a disadvantage: the health profile is only available on the web and for people with the required access, devices, skills and literacy. A purely digital approach may be beneficial for some groups of patients, but not for others, and should be supplemented by other options, such as waiting-room administered systems and outreach [55].

\section{Conclusions}

A personal digital health profile shows some promise as a component in a step-wise approach to preventive 
programs in primary care. Specifically, personal digital health profiles fulfil the aim of motivating people with low self-efficacy to attend, however not of motivating patients who had not had a health check or visited their GP during the past years. Further, women and patients with fair or poor self-rated health, a BMI above 30, low self-efficacy, sedentary behaviour and non-smokers were more likely to take up preventive programs in the primary care sector following a personal digital health profile. The uptake was similar across age, SES and health-care usage strata.

\begin{abstract}
Abbreviations
ATC: Anatomical Therapeutic Chemical Classification System; BMI: Body mass index; CHAID: Chi-squared Automatic Interaction Detection; COPD: Chronic Obstructive Pulmonary Disease; CPR: Danish Personal Identification number; CVD: Cardiovascular Disease; DAG: Direct Acyclic Graph; EPR: Electronic Patient Record; FEV1: Forced expiratory volume; FVC: Forced vital capacity; GP: General Practitioner; HbA1c: Glycated haemoglobin; HDL: High-density lipoprotein; ICD-10: International Classification of Diseases 10th Edition; ICPC-2: International Classification of Primary Care 2nd Edition; IRR: Incidence Rate Ratio; KEU: The joint Quality and educational committee of the Region of Southern Denmark; LDL: Low-density lipoprotein; MHC: Municipal Health Centre; MRC: Medical Research Council; NHS: National Health Services; OECD: Organisation for Economic Co-operation; PLO: Danish General Practitioners Union; SES: Socio-Economic Status; SWEMWBS: Short WarwickEdinburgh Mental Wellbeing Scale; T2DM: Type-2 Diabetes Mellitus; TOF: Project Early Detection and Prevention
\end{abstract}

\section{Acknowledgements}

Not applicable.

\section{Authors' contributions}

$L B L, J S, J L T, A H, A L S, J R C$ and $T$ participated in the design of the study. LBL analysed and interpreted the patient data and was the main contributor to the manuscript. LBL, JS, JLT, AH, ALS, JRC and TT contributed to the interpretation of patient data and the manuscript. LBL, JS, JLT, AH, ALS, JRC and $T T$ read and approved the final manuscript.

\section{Funding}

The project received funding from the Region of Southern Denmark and the Danish Ministry of Health. The funders have no role in the analysis, or interpretation of the data, writing of the article, or the decision to submit the paper for publication.

\section{Availability of data and materials}

The data that support the findings of this study will be available from Statistics Denmark but restrictions apply to the availability of these data, which will be used under license for the current study, and so are not publicly available. Data will however be available from the authors upon reasonable request and with permission of Statistics Denmark.

\section{Ethics approval and consent to participate}

The study was approved by the Danish Data Protection Agency (J.nr 2015-57-0008) and prospectively registered at Clinical Trial Gov (Unique Protocol ID: TOFpilot2016). According to Danish regulations (Act on Research Ethics Review of Health Research Projects (section 14,2)) this study does not need approval from a health research ethics committee as no research on human tissue or other biological material is performed. The study complies with the Helsinki declaration with informed consent to study participation and to disclosure of data from the GPs EPR obtained from all participants before enrolment. Participants were asked to read the information and electronically sign the consent form that was supplemented with short videos of the principal investigator and a GP describing the purpose of the study and the intervention. Before linking project data and national registers from Statistics Denmark participants were pseudomized. Data management and data analysis of quantitative data was performed on secure servers at Statistics Denmark.

\section{Consent for publication}

Not applicable.

\section{Competing interests}

The authors declare that they have no competing interests.

\section{Author details}

'Department of Public Health, Research Unit of General Practice, University of Southern Denmark, J.B. Winsløws Vej 9A, 5000 Odense, Denmark. 2Department of Clinical Medicine, Research Unit for General Practice, Aalborg University, Aalborg, Denmark. ${ }^{3}$ Department of Clinical Sciences in Malmö, Centre for Primary Health Care Research, Lund University, Lund, Sweden.

Received: 10 September 2018 Accepted: 31 July 2019

Published online: 13 August 2019

\section{References}

1. Si S, Moss JR, Sullivan TR, Newton SS, Stocks NP. Effectiveness of general practice-based health checks: a systematic review and meta-analysis. Br J Gen Pract. 2014;64(618):e47-53.

2. Simmons RK, Griffin SJ, Witte DR, Borch-Johnsen K, Lauritzen T, Sandbæk A. Effect of population screening for type 2 diabetes and cardiovascular risk factors on mortality rate and cardiovascular events: a controlled trial among 1,912,392 Danish adults. Diabetologia. 2017:23:1-9.

3. Ebrahim S, Taylor F, Ward K, Beswick A, Burke M, Davey SG. Multiple risk factor interventions for primary prevention of coronary heart disease. Cochrane Database Syst Rev. 2011;19(1):CD001561.

4. Blood Pressure Lowering Treatment Trialists' Collaboration. Blood pressurelowering treatment based on cardiovascular risk: a meta-analysis of individual patient data. Lancet Lond Engl. 2014;384(9943):591-8.

5. Cholesterol Treatment Trialists' (CTT) Collaborators, Mihaylova B, Emberson J, Blackwell L, Keech A, Simes J. m.fTThe effects of lowering LDL cholesterol with statin therapy in people at low risk of vascular disease: meta-analysis of individual data from 27 randomised trials. Lancet Lond Engl. 2012:380(9841):581-90.

6. Engelsen C d, Koekkoek PS, Godefrooij MB, Spigt MG, Rutten GE. Screening for increased cardiometabolic risk in primary care: a systematic review. Br J Gen Pract. 2014;64(627):e616-26.

7. Abdalrahman B, Soljak M. NHS health checks: an update on the debate and program implementation in England. J Ambulatory Care Manage marts. 2015;38(1):5-9.

8. van den Brekel-Dijkstra K, Rengers AH, Niessen MAJ, de Wit NJ, Kraaijenhagen RA. Personalized prevention approach with use of a web-based cardiovascular risk assessment with tailored lifestyle follow-up in primary care practice--a pilot study. Eur J Prev Cardiol marts. 2016;23(5):544-51.

9. Bruun Larsen L, Soendergaard J, Halling A, Thilsing T, Thomsen JL. A nove approach to population-based risk stratification, comprising individualized lifestyle intervention in Danish general practice to prevent chronic diseases: results from a feasibility study. Health Informatics I december. 2017:23(4):249-59.

10. Larsen LB, Sonderlund AL, Sondergaard J, Thomsen JL, Halling A, Hvidt NC. m.flTargeted prevention in primary care aimed at lifestyle-related diseases: a study protocol for a non-randomised pilot study. BMC Fam Pract. 2018;19:124.

11. Van der Meer V, Nielen MM, Drenthen AJ, Van Vliet M, Assendelft WJ, Schellevis FG. Cardiometabolic prevention consultation in the Netherlands: screening uptake and detection of cardiometabolic risk factors and diseases - a pilot study. BMC Fam Pract. 2013;14:29.

12. Pedersen KM, Andersen JS, Søndergaard J. General practice and primary health care in Denmark. J Am Board Fam Med. 2012;25(Suppl 1):S34-8.

13. Schneider $F$, van Osch $L$, de Vries $H$. Identifying factors for optimal development of health-related websites: A Delphi study among experts and potential future users. J Med Internet Res. 2012;14(1):e18.

14. Krist AH, Woolf SH. A vision for patient-centered health information systems JAMA. 2011;305(3):300-1.

15. Krist AH, Beasley JW, Crosson JC, Kibbe DC, Klinkman MS, Lehmann CU. m. flElectronic health record functionality needed to better support primary care. J Am Med Inform Assoc. 2014;21(5):764-71.

16. Martinez FJ, Raczek AE, Seifer FD, Conoscenti CS, Curtice TG, D'Eletto T. m. flDevelopment and Initial Validation of a Self-Scored COPD Population Screener Questionnaire (COPD-PS). COPD. 2008;5(2):85-95. 
17. Sandbaek A, Griffin SJ, Rutten G, Davies M, Stolk R, Khunti K. m.flStepwise screening for diabetes identifies people with high but modifiable coronary heart disease risk. The ADDITION study. Diabetologia juli. 2008;51(7):1127-34.

18. European Society of Cardiology. Heartscore webpage. (Archived by WebCite ${ }^{\oplus}$ at http://www.webcitation.org/6IN9ncXMD). Accessed 19 Oct 2016.

19. Danish Health Authority. Prevention guidelines - Alcohol. Copenhagen; 2018. https://www.sst.dk

20. Svenska Socialstyrelsen. Sjukdomsförebyggande metoder. Vetenskabeligt underlag för nationella riktlinjer. Svenska Socialstyrelsen; 2011.

21. Stewart-Brown S, Tennant A, Tennant R, Platt S, Parkinson J, Weich S. Internal construct validity of the Warwick-Edinburgh mental well-being scale (WEMWBS): a Rasch analysis using data from the Scottish health education population survey. Health Qual Life Outcomes. 2009;7:15.

22. Scholz U, Gutiérrez Doña B, Sud S, Schwarzer R. Is general self-efficacy a universal construct? Eur J Psychol Assess. 2002;18:242-51.

23. Larsen LB, Sandbaek A, Thomsen JL, Bjerregaard A-L. Uptake of health checks by residents from the Danish social housing sector - a register-based cross-sectional study of patient characteristics in the 'Your Life - Your Health' program. BMC Public Health. 2018;18(1):585

24. Shrier I, Platt RW. Reducing bias through directed acyclic graphs. BMC Med Res Methodol. 2008;8:70

25. Greenland S. Interpretation and choice of effect measures in epidemiologic analyses. Am J Epidemiol maj. 1987;125(5):761-8.

26. Zou G. A modified poisson regression approach to prospective studies with binary data. Am J Epidemiol. 2004;159(7):702-6.

27. Barros AJ, Hirakata VN. Alternatives for logistic regression in cross-sectional studies: an empirical comparison of models that directly estimate the prevalence ratio. BMC Med Res Methodol. 2003;3:21.

28. Kass GV. An exploratory technique for investigating large quantities of categorical data. J R Stat Soc Ser C Appl Stat. 1980;29(2):119-27.

29. Hermsen S, Frost J, Renes RJ, Kerkhof P. Using feedback through digital technology to disrupt and change habitual behavior: A critical review of current literature. Comput Hum Behav. 2016:57:61-74.

30. Norman P. Applying the health belief model to the prediction of attendance at health checks in general practice. Br J Clin Psychol. 1995;34(Pt 3):461-70.

31. Koopmans B, Nielen MM, Schellevis FG, Korevaar JC. Non-participation in population-based disease prevention programs in general practice. BMC Public Health. 2012;12:856.

32. Larsen LB, Sondergaard J, Thomsen JL, Halling A, Sønderlund AL, Christensen JR. m.flDigital recruitment and acceptance of a stepwise model to prevent chronic disease in the Danish primary care sector: cross-sectional study. J Med Internet Res. 2019:21(1):e11658.

33. Choices NHS. NHS Health Check. https://www.nhs.uk/conditions/nhs-healthcheck/. Accessed 08 Aug 2019.

34. Thorogood M, Coulter A, Jones L, Yudkin P, Muir J, Mant D. Factors affecting response to an invitation to attend for a health check. J Epidemiol Community Health. 1993;47(3):224-8.

35. Dalton ARH, Bottle A, Okoro C, Majeed A, Millett C. Uptake of the NHS Health Checks programme in a deprived, culturally diverse setting: cross-sectional study. J Public Health. 2011;33(3):422-9.

36. Lang S-J, Abel GA, Mant J, Mullis R. Impact of socioeconomic deprivation on screening for cardiovascular disease risk in a primary prevention population: a cross-sectional study. BMJ Open. 2016;6(3).

37. Gidlow C, Ellis N, Randall J, Cowap L, Smith G, Iqbal Z. m.flMethod of invitation and geographical proximity as predictors of NHS Health Check uptake. J Public Health. 2015;37(2):195-201.

38. Bjerregaard A-L, Maindal HT, Bruun NH, Sandbæk A. Patterns of attendance to health checks in a municipality setting: the Danish 'check your health preventive program'. Prev Med Rep. 2017;5:175-82.

39. Cochrane T, Gidlow CJ, Kumar J, Mawby Y, lqbal Z, Chambers RM. Cross-sectional review of the response and treatment uptake from the NHS health checks programme in Stoke on Trent. J Public Health Oxf Engl. 2013;35(1):92-8.

40. Cook EJ, Sharp C, Randhawa G, Guppy A, Gangotra R, Cox J. Who uses NHS health checks? Investigating the impact of ethnicity and gender and method of invitation on uptake of NHS health checks. Int J Equity Health. 2016;15:13.

41. Hoebel J, Starker A, Jordan S, Richter M, Lampert T. Determinants of health check attendance in adults: findings from the cross-sectional German health update (GEDA) study. BMC Public Health. 2014;14(1):913.
42. Dryden R, Williams B, McCowan C, Themessl-Huber M. What do we know about who does and does not attend general health checks? Findings from a narrative scoping review. BMC Public Health. 2012;12:723.

43. Bender AM, Jørgensen $T$, Helbech B, Linneberg A, Pisinger C. Socioeconomic position and participation in baseline and follow-up visits: the Inter99 study. Eur J Prev Cardiol. 2014;21(7):899-905.

44. Murray J, Craigs CL, Hill KM, Honey S, House A. A systematic review of patient reported factors associated with uptake and completion of cardiovascular lifestyle behaviour change. BMC Cardiovasc Disord. 2012;12:120.

45. Bandura A. Self-efficacy: toward a unifying theory of behavioral change. Psychol Rev. 1977:84(2):191-215.

46. Shaw RL, Holland C, Pattison HM, Cooke R. Patients' perceptions and experiences of cardiovascular disease and diabetes prevention programmes: A systematic review and framework synthesis using the Theoretical Domains Framework. Soc Sci Med 1982. 2016;156:192-203.

47. Bandura A. Health promotion by social cognitive means. Health Educ Behav Off Publ Soc Public Health Educ. 2004;31(2):143-64.

48. Jørgensen T, Borch-Johnsen $\mathrm{K}$, Thomsen TF, Ibsen H, Glümer C, Pisinger C. A randomized non-pharmacological intervention study for prevention of ischaemic heart disease: baseline results Inter99 (1). Eur J Cardiovasc Prev Rehabil. 2003;10(5):377-86.

49. Lauritzen T, Leboeuf-Yde C, Lunde IM, Nielsen KD. Ebeltoft project: baseline data from a five-year randomized, controlled, prospective health promotion study in a Danish population. Br J Gen Pract. 1995:45(399):542-7.

50. van den Donk M, Sandbaek A, Borch-Johnsen K, Lauritzen T, Simmons RK, Wareham NJ. m.flScreening for type 2 diabetes. Lessons from the ADDITIONEurope study. Diabet Med J Br Diabet Assoc. 2011;28(11):1416-24.

51. Provost S, Pineault R, Grimard D, Pérez J, Fournier M, Lévesque Y. m. fllmplementation of an integrated primary care cardiometabolic risk prevention and management network in Montréal: does greater coordination of care with primary care physicians have an impact on health outcomes? Health Promot Chronic Dis Prev Can Res Policy Pract. 2017;37(4):105-13.

52. Grandes G, Sanchez A, Cortada JM, Pombo H, Martinez C, Balagué L. m.flCollaborative modeling of an implementation strategy: a case study to integrate health promotion in primary and community care. BMC Res Notes. 2017;10(1):699.

53. Thygesen LC, Daasnes C, Thaulow I, Brønnum-Hansen H. Introduction to Danish (nationwide) registers on health and social issues: Structure, access, legislation, and archiving. Scand J Public Health. 2011:39(7 suppl):12-6.

54. Andersen JS, Olivarius NDF, Krasnik A. The Danish National Health Service Register. Scand J Public Health. 2011;39(7 Suppl):34-7.

55. Ebert JF, Huibers L, Christensen B, Christensen MB. Paper- or web-based questionnaire invitations as a method for data collection: cross-sectional comparative study of differences in response rate, completeness of data, and financial cost. J Med Internet Res. 2018;20(1):e24.

\section{Publisher's Note}

Springer Nature remains neutral with regard to jurisdictional claims in published maps and institutional affiliations.

Ready to submit your research? Choose BMC and benefit from:

- fast, convenient online submission

- thorough peer review by experienced researchers in your field

- rapid publication on acceptance

- support for research data, including large and complex data types

- gold Open Access which fosters wider collaboration and increased citations

- maximum visibility for your research: over $100 \mathrm{M}$ website views per year

At BMC, research is always in progress.

Learn more biomedcentral.com/submissions 